\title{
An Analysis of Research Trends in the Use and Abuse of Alcohol by Adolescents: Papers Published in Korean Academic Journals
}

\author{
Eunsil Kim \\ Dept. of Child Welfare, Namseoul University, Korea \\ gender@hanmail.net
}

\begin{abstract}
The purpose of this study was to analyze trends of alcohol use and abuse researches among adolescents by analyzing journal articles in Korean. To do this, 190 papers published until 2017 were extracted and analyzed according to the content analysis procedure, focusing on the publication year, the research topics, and research methods. Results showed that the number of studies related to alcohol use and abuse among adolescents began to increase from the late 1990s and has risen since the early 2000s. 'Relationship' was the most frequently researched topic, accounting for $71.0 \%$, followed by 'Current Status' (11.0\%), 'Prevention' (6.6\%), 'Law and Policies' (3.7\%), 'Characteristics' (3.2\%), 'Review and Theory' (2.1\%), 'Scales' (1.6\%), and 'Intervention' (0.5\%). The research methods were quantitative (86.0\%), qualitative (10.0\%) and mixed (3.7\%).
\end{abstract}

Keywords: Use, Abuse, Adolescents, Research trends, Content analysis

\section{Introduction}

Adolescents' alcohol consumption not only affects them physically but also has enormous effects on mental health and problem behaviors. Its diverse effects may manifest from the short to the long term. Drinking increases the risks of car accidents, delinquency, and pregnancy in adolescents [1][2]. Continuous drinking causes dermatitis as well as problems in the cardiovascular and digestive systems [3][4], and has negative mental effects such as developing depression or anxieties [5]. In the long term, it affects brain development [6][7], bone mineral density [8], liver disease [9], and production of male and female hormones [10]. Furthermore, it increases the risks of suicidal behaviors [11], alcoholism [12], and many other diseases including cirrhosis and cancer [13][14][15]. In brief, adolescent drinking entails increased burden and costs to both to individuals and society [16][17].

Adolescent drinking is not a problem unique to Korea, but one of the serious problems that concern many countries around the world. According to the World Health Organization (WHO) [18], globally about $16.0 \%$ drinkers aged 15 years or older engage in heavy episodic drinking and about 3.3 million deaths were attributable to alcohol consumption in 2012. In Korea, the alcohol drinking rate of male students in middle and high schools was recorded at $17.2 \%$, and that of female students at $12.5 \%$ [19]. The age of first drinking experience was 13.2 years. Although this tendency is now on a continuous decrease compared to the drinking

Article history:

Received (May 19, 2018), Review Result (July 20, 2018), Accepted (October 18, 2018) 
rate of male students of $30.5 \%$ and of female students of $26.5 \%$ in 2006 , the prevalence of drinking is still quite high.

Hence, researchers have continued to investigate the use and abuse of alcohol by adolescents. Nonetheless, only little is known about whether the existing body of literature reflects the practical needs related to adolescent problems and whether such efforts take balanced approaches to understand the phenomenon and to simultaneously suggest effective prevention and intervention measures. In this context, this study analyzed the research trends in existing studies on the alcohol use and abuse patterns of adolescents, which were published in Korean academic journals. It compared the trends with those of other various existing studies on addiction patterns and the use and abuse of alcohol by adolescents in other countries. Based on the comparative analysis, this study offers several implications from the results and a direction for future development of studies on the use and abuse of alcohol by adolescents.

\section{Materials and methods}

\subsection{Materials}

Research papers analyzed in this study were extracted from the Research Information Service System of Korea (www.riss.kr), National Assembly Library of the Republic of Korea (www.nanet.go.kr), and National Library of Korea (www.nl.go.kr) using the search engine of each site. Keywords were "alcohol" and "drinking." Among all papers found, a total of 190 papers examining adolescents (from 5th grade in elementary to 3rd grade in high school), which had been published in Korean academic journals until 2017, were finally selected. Papers were selected by 3 experts who were certified addiction counseling specialists (1 professor of addiction rehabilitation counseling, 1 professor of education counseling, and 1 doctoral course student of child counseling). For this study, papers were limited to those published in academic journals only. Papers published in magazines and academic conference proceedings, and those presented at poster sessions were thus excluded.

\subsection{Procedures}

This study applied content analysis, which is a method considered suitable for examining how studies of a certain academic research area evolves over a long period of time [20][21]. The analysis was conducted according to the following procedures. First, publication year, paper's title, topic, participants, and method were extracted from selected papers. Second, rating guidelines were established to ensure accurate coding of extracted data. The validity of the guidelines was first tested by 1 professor of addiction counseling, and the guidelines were finalized after correction. Third, the 3 experts who had participated in data selection practiced coding together to increase the inter-rater agreement. Finally, all papers for analysis were coded separately by each rater, and the results were compared. When coding results did not correspond, the raters adjusted them through discussion. The rating process and results were tested by 1 professor of addiction counseling.

\subsection{Coding and analysis methods}

In coding the rated results, 1 was assigned to each paper of the rated categories [22]. If 1 paper belonged to 2 or more categories, 1 was divided by the number of categories and the 
resulting number was assigned. The total number of papers belonging to each category was calculated and analyzed through frequency analysis and cross tabulation.

\section{Results}

Studies of the use and abuse of alcohol by adolescents began to be published from 1967, and 1 to 2 papers were published every year until the late 1990s. The number started to grow from the late 1990s, and rose sharply from early 2000. The period between 2005 and 2009 saw the most number of papers published, with average 10.2 papers published in academic journals every year [Table 1] and [Figure 1].

Table 1. Annual numbers of published papers

\begin{tabular}{|c|c|c|c|c|c|c|c|c|}
\hline Year & $n$ & $\%$ & Year & $n$ & $\%$ & Year & $n$ & $\%$ \\
\hline 1967 & 1 & 0.5 & 1998 & 3 & 1.6 & 2009 & 18 & 9.5 \\
\hline 1979 & 1 & 0.5 & 1999 & 7 & 3.7 & 2010 & 10 & 5.3 \\
\hline 1983 & 3 & 1.6 & 2000 & 4 & 2.1 & 2011 & 5 & 2.6 \\
\hline 1984 & 2 & 1.1 & 2001 & 6 & 3.2 & 2012 & 12 & 6.3 \\
\hline 1985 & 1 & 0.5 & 2002 & 8 & 4.2 & 2013 & 10 & 5.3 \\
\hline 1986 & 2 & 1.1 & 2003 & 8 & 4.2 & 2014 & 11 & 5.8 \\
\hline 1987 & 1 & 0.5 & 2004 & 6 & 3.2 & 2015 & 13 & 6.8 \\
\hline 1988 & 1 & 0.5 & 2005 & 6 & 3.2 & 2016 & 9 & 4.7 \\
\hline 1995 & 3 & 1.6 & 2006 & 10 & 5.3 & 2017 & 8 & 4.2 \\
\hline 1996 & 2 & 1.1 & 2007 & 8 & 4.2 & - & - & - \\
\hline 1997 & 2 & 1.1 & 2008 & 9 & 4.7 & Total & 190 & 100 \\
\hline
\end{tabular}

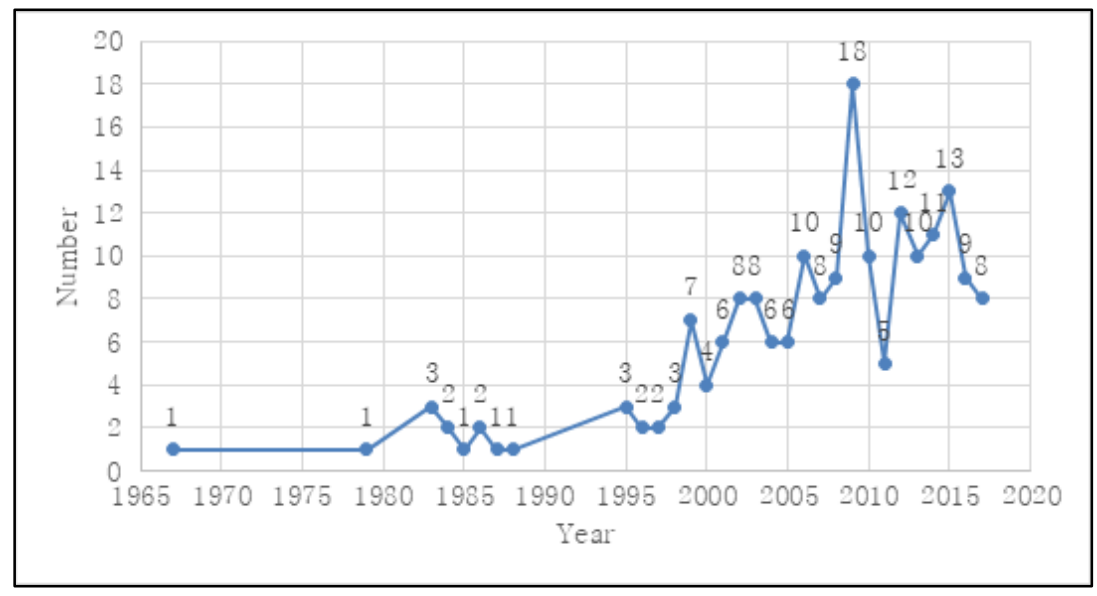

Figure 1. The yearly trend of numbers of published papers

By study topic, 134.5 papers (71.0\%) examined relationship, investigating factors influencing drinking or those influenced by drinking, which was more than $2 / 3$ of the total number of papers (see table 2). This was followed by 21 papers on status (11.0\%), 12.5 on prevention (6.6\%), and 8 on law and policies $(4.2 \%)$. Scales and interventions were least researched topics, both accounting for 3 papers or less. Status studies were conducted relatively steadily from the late 1970s, whereas the number of relationship studies rose rapidly since the late 1990s, continuously increasing until the early and mid-2010s. 
Prevention was studied from late 1990s. It was studied most frequently in the early 2000s, but the figure started to decline afterward.

Table 2. Annual numbers of published papers by study topic

\begin{tabular}{|c|c|c|c|c|c|c|c|c|c|c|}
\hline Years & $\begin{array}{l}65- \\
‘ 69 \\
\end{array}$ & $\begin{array}{l}\cdot 75- \\
\cdot 79 \\
\end{array}$ & $\begin{array}{l}\text { '80- } \\
\text { '84 }\end{array}$ & $\begin{array}{l}85- \\
\text { '89 } \\
\end{array}$ & $\begin{array}{l}95- \\
\text { '99- } \\
\end{array}$ & $\begin{array}{l}00- \\
' 04 \\
\end{array}$ & $\begin{array}{l}05- \\
\text { '09 } \\
\end{array}$ & $\begin{array}{l}\text { '10- } \\
\text { '14 }\end{array}$ & $\begin{array}{l}15- \\
' 17 \\
\end{array}$ & Total \\
\hline Review and Theory & 0 & 0 & 0 & 0 & 0 & 2 & 1 & 0 & 1 & 4 \\
\hline Status & 0 & 1 & 2 & 1 & 3.5 & 5.5 & 5.5 & 1 & 1.5 & 21 \\
\hline Characteristics & 0 & 0 & 0 & 0 & 0 & 1 & 4 & 0 & 1 & 6 \\
\hline Scales & 0 & 0 & 0 & 0 & 2 & 0 & 0 & 0 & 1 & 3 \\
\hline Relationship & 0 & 0 & 3 & 4 & 8.5 & 17.5 & 33.5 & 44.5 & 23.5 & 134.5 \\
\hline Prevention & 0 & 0 & 0 & 0 & 2 & 5 & 3 & 0.5 & 2 & 12.5 \\
\hline Intervention & 0 & 0 & 0 & 0 & 0 & 0 & 1 & 0 & 0 & 1 \\
\hline Law\&Policies & 1 & 0 & 0 & 0 & 1 & 1 & 3 & 2 & 0 & 8 \\
\hline Sum & 1 & 1 & 5 & 5 & 17 & 32 & 51 & 48 & 30 & 190 \\
\hline
\end{tabular}

By study method, 19 papers employed qualitative methods (10.0\%), 164 employed quantitative methods (86\%), and 7 employed mixed methods (3.7\%) [Table 3]. Most papers applying qualitative methods collected data through literature review, and only one study obtained data through interview. Among papers using quantitative method, authors of 106 papers collected data themselves through survey, accounting for $57 \%$ of total papers. Fifty used panel data from governmental agencies (26.3\%).

Table. 3 Annual numbers of published papers by study methods

\begin{tabular}{|c|c|c|c|c|c|c|c|c|c|c|c|}
\hline $\begin{array}{l}\text { Research } \\
\text { Method }\end{array}$ & $\begin{array}{c}\text { Data } \\
\text { Collection }\end{array}$ & $\begin{array}{r}\text { '65 } \\
-' 69\end{array}$ & $\begin{array}{r}' 75 \\
-' 79\end{array}$ & $\begin{array}{r}' 80 \\
-' 84\end{array}$ & $\begin{array}{r}\text { ' } 85 \\
-' 89\end{array}$ & $\begin{array}{r}\text { '95 } \\
-' 99\end{array}$ & $\begin{array}{r}' 00 \\
-04\end{array}$ & $\begin{array}{r}‘ 05 \\
-' 09\end{array}$ & $\begin{array}{r}' 10 \\
-' 04\end{array}$ & $\begin{array}{r}' 15 \\
-' 17\end{array}$ & Total \\
\hline \multirow[t]{2}{*}{ Qualitative } & $\begin{array}{c}\text { Literature } \\
\text { Review }\end{array}$ & 1 & 0 & 0 & 0 & 4 & 5 & 5 & 2 & 1 & 18 \\
\hline & Interview & 0 & 0 & 0 & 0 & 0 & 0 & 1 & 0 & 0 & 1 \\
\hline \multirow{4}{*}{ Quantitative } & Survey & 0 & 1 & 4 & 5 & 13 & 23 & 34 & 20 & 8 & 108 \\
\hline & Experiment & 0 & 0 & 0 & 0 & 0 & 3 & 3 & 0 & 0 & 6 \\
\hline & Panel $\left(C^{a}\right)$ & 0 & 0 & 1 & 0 & 0 & 1 & 4 & 18 & 16 & 40 \\
\hline & Panel $\left(\mathrm{L}^{\mathrm{b}}\right)$ & 0 & 0 & 0 & 0 & 0 & 0 & 2 & 5 & 3 & 10 \\
\hline Mixed & - & 0 & 0 & 0 & 0 & 0 & 0 & 2 & 3 & 2 & 7 \\
\hline Total & - & 1 & 1 & 5 & 5 & 17 & 32 & 51 & 48 & 30 & 190 \\
\hline
\end{tabular}

\section{Conclusions}

This study analyzed papers published in Korean academic journals, aiming to identify the trends of studies on the use and abuse of alcohol by adolescents. An analysis of 190 papers published until 2017 showed that the number of papers examining adolescents' use and abuse of alcohol started to increase from the late 1990s, and sharply rose since the early 2000s. The highest number of papers was published between 2005 and 2009. A vast majority of study participants were normal adolescents accounting for $84.8 \%$ papers. A large number of papers focused on relationship studies $(71.0 \%)$. Few papers were dedicated to topics such as status $(11.0 \%)$, prevention $(6.6 \%)$, law and policies $(3.7 \%)$, characteristics $(3.2 \%)$, Review and Theory $(2.1 \%)$, scales $(1.6 \%)$, and intervention $(0.5 \%)$. A vast majority of papers used quantitative methods $(86.0 \%)$. Few papers employed qualitative $(10.0 \%)$ and mixed methods $(3.7 \%)$. Future studies are suggested to explore a wider range of topics concerning the use and 
abuse of alcohol by adolescents, such as prevention and intervention. A balanced research approach using both qualitative and mixed methods is also recommended.

\section{References}

[1] M.H. Swahn, T.R. Simon, B.J. Hammig, and J.L. Guerrero, “Alcohol-consumption behaviors and risk for physical fighting and injuries among adolescent drinkers," Addictive Behaviors, vol.29, no.5, pp.959-963, (2004)

[2] J. Deardorff, N.A. Gonzales, F.S. Christopher, M.W. Roosa, and R.E. Millsap, "Early puberty and adolescent pregnancy: The influence of alcohol use," Pediatrics, vol.116, no.6, pp.1451-1456, (2005)

[3] J. Rehm, C.T. Sempos, and M. Trevisan, "Alcohol and cardiovascular disease-more than one paradox to consider: Average volume of alcohol consumption, patterns of drinking and risk of coronary heart disease a review," Journal of Cardiovascular Risk, vol.10, no.1, pp.15-20, (2003)

[4] C. Bode and J.C. Bode, "Alcohol's role in gastrointestinal tract disorders," Alcohol Health and Research World, vol.21, no.1, pp.76-83, (1997)

[5] J.M. Boden and D.M. Fergusson, "Alcohol and depression," Addiction, vol.106, no.5, pp.906-914, (2011)

[6] L. Spear, "Modeling adolescent development and alcohol use in animals," Alcohol Research and Health, vol.24, no.2, pp.115-123, (2000)

[7] S. Bava and S.F. Tapert, "Adolescent brain development and the risk for alcohol and other drug problems," Neuropsychology Review, vol.20, no.4, pp.398-413, (2010)

[8] N.S. Joo, M.H. Kong, B.T. Kim, S.B. Park, T.Y. Lee, and K.M. Kim, "Impact of smoking and alcohol intake on bone mineral density in men," Korean Journal of Family Medicine, vol.27, no.11, pp.911-916, (2006)

[9] C.S. Lieber, "Relationships between nutrition, alcohol use, and liver disease," Alcohol Research \& Health, vol.27, no.3, pp.220-231, (2003)

[10] A. Erol, A.M. Ho, S.J. Winham, and V.M. Karpyak, "Sex hormones in alcohol consumption: A systematic review of evidence," Addiction Biology, (2017) DOI:10.1111/adb.12589

[11] E.A. Schilling, R.H. Aseltine, J.L. Glanovsky, A. James, and D. Jacobs,"Adolescent alcohol use, suicidal ideation, and suicide attempts," Journal of Adolescent Health, vol.44, no.4, pp.335-341, (2009)

[12] G.F. Grant, "The impact of a family history of alcoholism on the relationship between age at onset of alcohol use and DSM-IV alcohol dependence: Results of the national longitudinal alcohol epidemiologic survey," Alcohol Health \& Research World, vol.22, pp.144-147, (1998)

[13] J.J. Maher, "Exploring alcohol's effects on liver function," Alcohol Health and Research World, vol.21, no.1, pp.5-12, (1997)

[14] J. Rehm, R. Room, K. Graham, M. Monteiro, G. Gmel, and C.T. Sempos, "The relationship of average volume of alcohol consumption and patterns of drinking to burden of disease: An overview," Addiction, vol. 98, no. 9, pp.1209-1228, (2003)

[15] V. Bagnardi, M. Blangiardo, L.V. Carlo, and G. Corrao, "Alcohol consumption and the risk of cancer: A meta-analysis," Alcohol Research and Health, vol.25, no.4, pp.263-70, (2001)

[16] J. Kim, W. Chung, S. Lee, and C. Park, "Estimating the socioeconomic costs of alcohol drinking among adolescents in Korea," Journal of Preventive Mecicine and Public Health, vol.43, no.4, pp.341-351, (2010)

[17] S. Lee, W. Chung, I.S. Kim, H.J. Kim, W. Cho, E. Shin, S.H. Ahn, K.H. Han, and J.I. Myoung, "Socioeconomic costs of alcohol drinking in Korea," Korean Journal of Family Medicine, vol.29, no.3, pp.201-212, (2008)

[18] World Health Organization, Global status report on alcohol and health 2014, Retrieved from http://www.who.int/substance_abuse/publications/global_alcohol_report/en, Sep 15, (2018)

[19] Ministry of Education, Ministry of Health and Welfare, Korea Centers for Disease Control \& Prevention, The Twelfth Korea Youth Risk Behavior Web-based Survey 2016 Report, Korea Centers for Disease Control \& Prevention, Seoul, Korea (2016) 
[20] K.T. Mahoney, W.C. Buboltz, B. Soper, D. Doverspike, and B.J. Simoneaux, "Content analysis of Consulting psychology journal: Practice and research (Volumes 44-59)," Consulting Psychology Journal: Practice and Research, vol.60, no.3, pp.246-258, (2008)

[21] A. Rubin, and E. Babbie, "Essential research methods for social work (3rd ed.)," Brooks/Cole, Belmont, CA, (2012)

[22] W.C. Bublotz, M. Miller, and D.J. Williams, "Content analysis of research in the journal of counseling psychology (1973-1998),” Journal of Counseling Psychology, vol.46, no.4, pp.496-503, (1999)

\section{Author}

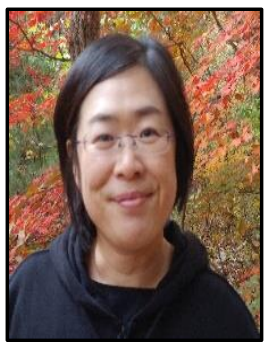

\section{Eunsil Kim}

- Assistant Professor, Dept. of Child Welfare, Namseoul University - Chief Manager in Namseoul University Student Counseling Center - Director of Addiction Rehabilitation Counseling Program in Namseoul University Graduate School 